\title{
Government Support for Open Educational Resources : Policy, Funding, and Strategies
}

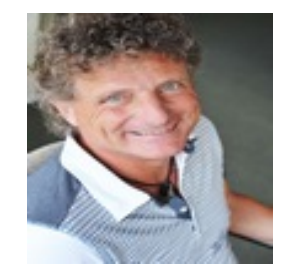

Paul Stacey

Canada

\section{Abstract}

Foundations like Hewlett, Mellon, and Gates provided start-up funding and support that nurtured the field of open educational resources (OER) from infancy to a robust early adolescence characterized by energy and idealism (Casserly \& Smith, 2008). However, foundation grants typically focus on establishing exemplars and cannot be relied on for sustaining ongoing operations or generating widespread adoption. One strategy for sustaining and expanding OER is for governments and public funding to take over from the early stage funding foundations provided (Stacey, 2010).

Keywords : Open education resources; policy; funding; strategies 


\section{Introduction}

There is a growing awareness of the potential role government and public funds can play in the OER field. The UNESCO-COL Guidelines for Open Educational Resources (OER) in Higher Education provide a set of guidelines to support governments, teaching staff, higher education institutions/providers, and quality assurance/accreditation and recognition bodies.

The guidelines for government include the following:

a. support the use of OER through the revision of policy regulating higher education,

b. contribute to raising awareness of key OER issues,

c. review national ICT/ connectivity strategies for higher education,

d. consider adapting open licensing frameworks,

e. consider adopting open format standards,

f. support institutional investments in curriculum design,

g. support the sustainable production and sharing of learning materials,

h. collaborate to find effective ways to harness OER. (Daniel, 2011)

This set of guidelines is complementary to and more tightly focused on government than the 2007 Cape Town Declaration. The Cape Town Declaration is a statement of principle, strategy, and commitment meant to spark dialogue, inspire action, and help the open education movement grow. The full declaration describes OER as a global revolution in teaching and learning with educators worldwide developing a vast pool of educational resources on the Internet, open and free for all to use. The declaration defines three strategies:

1. encourage educators and learners to actively participate in the emerging open education movement;

2. call on educators, authors, publishers and institutions to release their resources openly;

3. encourage governments, school boards, colleges and universities to make open education a high priority. (Shuttleworth, 2007)

The declaration invites all individuals and institutions to join in signing the Cape Town Open Education Declaration, and, in doing so, to commit to pursuing the three 
strategies listed above. As of October 30, 2011, 2,283 individuals and 242 organizations had added their names to the declaration.

\section{Policy}

OER will flourish when bottom-up grassroots OER development takes place in an environment supported top-down by policy. Government support for OER can happen at the policy and guidelines level without any additional funding. The UNESCO-COL guidelines identify several zero sum strategies. Revision of policy and the adoption of open licensing frameworks are two areas that have early adoption.

In parallel with the emergence of OER there is growing government interest in making resources produced through tax dollars publicly accessible. Whether it be the UK national government or the author's own provincial government of British Columbia (BC) open government initiatives are using policy and legal frameworks to open up access to publicly held information, promoting transparency and enabling wider economic and social gain. Initially, these efforts have been focused on openly releasing data to promote creative and innovative activities, which will deliver social and economic benefits; make government more transparent and open in its activities, ensuring that the public are better informed about the work of the government and the public sector; and enable more civic and democratic engagement through social enterprise and voluntary and community activities (UK Government, 2011) (BC Government, 2011).

Release of open data is being done by open government licenses. While initially focused on data sets, these efforts to make government more open and transparent have potential applicability to education. The rationale being used to support open data equally applies to education, and all governments could establish policy that requires public funds for education to result in education resources openly accessible to the public. Some governments have provided funding for development of educational resources under agreements that have the IP and copyright for those resources resting with the government. Governments could easily convert all these legacy educational resources to OER by simply using an open license.

One example of a government going a step further is the New Zealand Government's Open Access and Licensing framework (NZGOAL) which focuses not just on data sets but on the vast quantities of copyright works, research reports, statistics, photographic images, educational resources, and archive film produced through State Services agencies. New Zealand changed the policy to standardize the licensing of government copyright works for reuse using Creative Commons licenses (New Zealand Government, 2010). From the perspective of schools, the copyright of all teaching materials produced by educators vests with the Board of Trustees. NZGOAL encourages boards of trustees to use the least restrictive of licenses with Creative Commons Attribution as the default. 
Policy requiring open licensing of education resources can also be implemented at the city or institutional level. The city of Sao Paulo in Brazil has decreed that all educational resources paid for by the city need to be OER licensed using a Creative Commons license (CC-BY-NC-SA) (Sao Paulo, 2011).

At the policy level there is growing interest in seeing tax dollars used to create education materials that are openly licensed for public use. The default policy should be open not closed, collaborative not proprietary, and accessible not restricted (Carlyle, 2011).

Education demand far exceeds supply and all public governments are seeking ways to provide more and better education for more people. The biggest potential for immediate gain is to adopt a policy that publicly funded education materials be openly licensed and available to the public that funded them. Publicly funded educational resources would become open educational resources by default. OER would become outputs of normal every day work. This policy could apply not just to new educational resources, but to legacy resources where copyright and intellectual property is held by the government.

While many governments are still considering guidelines, others are already taking an active role and have launched publicly funded OER initiatives. This paper examines three publicly funded OER initiatives already underway in three different countries. The strategies and tactics of these OER case studies show how some public funders have pioneered government support and funding for OER programs. These early government OER examples provide an interesting baseline of activity to compare against the UNESCO-COL OER guidelines. By making existing publicly funded OER strategies and practices more visible it becomes easier to see how these guidelines translate into practice which in turn supports other public funders in designing and launching their own OER initiatives.

The three government funded OER initiatives explored in this paper are

1. Canada, BCcampus Online Program Development Fund;

2. United Kingdom, J oint Information Systems Committee (J ISC) and the Higher Education Academy (Academy) Open Educational Resources Program;

3. United States, Department of Labor Trade Adjustment Assistance Community College and Career Training Grants Program (TAACCCT). 


\section{Funding}

In parallel with adoption of guidelines and revision of policies most public funders are providing OER incentive funding.

The BCcampus OER program is being funded by the British Columbia provincial government's Ministry of Advanced Education. It has been deployed as an annual Online Program Development Fund call for proposals issued to BC's public postsecondary institutions. To date there have been eight annual rounds, 2003-2010, totaling \$9 million dollars.

The J ISC OER program is being funded by The Higher Education Funding Council for England (HEFCE). The Higher Education Funding Council for England (HEFCE) distributes public money to universities and colleges in England that provide higher education. Most of this goes to the 130 universities and higher education colleges in England. There have been three phases of the J ISC OER program : Phase one (20092010) £5.7m, Phase two (2010-2011) £5m, and Phase three (2011-2012) £2.8m totaling $£ 13.5 \mathrm{~m}$ or roughly $\$ 21$ million US dollars. Funding in each of these phases has been made available via a "call for projects" issued to institutions.

One of the interesting things about the Trade Adjustment Assistance Community College and Career Training (TAACCCT) Grants Program is that it is being initiated out of the US Department of Labor as opposed to the education ministry as in the other two examples. The first round of TAACCCT grants made available and awarded in 2011 totals $\$ 500$ million but a total of $\$ 2$ billion over four years has been committed. Funds are being made available through a Notice of Availability of Funds and Solicitation for Grant Applications announcement targeted to eligible institutions of higher education in the 50 states, the District of Columbia, and Puerto Rico.

The dollars invested in OER through these three publicly funded initiatives varies from $\$ 9$ million to $\$ 2$ billion. One way of comparing the relative magnitude of these investments to one another is to factor in size of the target population served and the duration of the investment. 
Table 1

OER Funding Comparison

\begin{tabular}{|l|l|l|l|}
\hline OER & $\begin{array}{l}\text { OER funding } \\
\text { initiative }\end{array}$ & Funding & Number of \\
investment & years & years \\
\hline BCcampus & $\$ 9,000,000$ & $2003-2010$ & 8 \\
\hline J ISC & $\$ 21,000,000$ & $2009-2012$ & 3 \\
\hline TAACCCT & $\$ 2,000,000,000$ & $2011-2014$ & 4 \\
\hline
\end{tabular}

\begin{tabular}{|l|l|l|l|l|}
\hline \multirow{2}{*}{ OER } & & & Per capita & Per yr \\
initiative & Jurisdiction & Population & investment & investment \\
\hline BCcampus & BC, Canada & $4,419,974$ & $\$ 2.04$ & $\$ 0.25$ \\
\hline J ISC & England, UK & $51,456,400$ & $\$ 0.41$ & $\$ 0.14$ \\
\hline TAACCCT & US \& & $316,085,789$ & $\$ 6.33$ & $\$ 1.58$ \\
& Puerto Rico & & & \\
\hline
\end{tabular}

Per Capita Investment = OER Funding Investment/ Population

Per Capita/ Per Year Investment = OER Funding Investment/ Population/ Number of Years

Population Count Sources:

British Columbia http:// en.wikipedia.org/ wiki/British_Columbia (2009 population count)

England http:// en.wikipedia.org/wiki/Demography_of_England (2008 population count)

United States http://en.wikipedia.org/wiki/Demographics_of the_United_States (2011 population count $312,360,000)$

Puerto Rico http:// en.wikipedia.org/wiki/Puerto_Rico (2010 population count 3,725,789) 
The $\mathrm{BC}$ per person investment in OER is about five times larger than the UK investment but a third of the size of the US. The US is investing over six times more than BC and eleven times more than the UK on a per person per year basis.

Public funders must determine how to complement policy and guidelines with funding investments in OER. Other publicly funded government initiatives who, after considering the COL-UNESCO guidelines, decide to initiate OER programs should be considering investments in the range of a low of $\$ .14$ per person/per year to a high of $\$ 1.58$ per person/per year. Whether you invest at the high end or the low end depends on the importance of your strategic goals.

This per capita/ per year analysis of public funding for OER can be complemented by a deeper analysis. Additional comparisons could be done based on numbers of postsecondary students enrolled in each jurisdiction rather than total population. It's also worth looking at the actual products generated through these funds.

The BCcampus funds have been targeted exclusively to the development of OER programs, courses, and course components. The main outcomes to date are:

- 144 grants awarded (2003-2010);

- $\quad 100 \%$ participation across the post-secondary system;

- $\quad 83 \%$ partnerships - mostly inter-institutional but also with $\mathrm{K}-12$, health authorities, not-for-profits, professional associations, e-learning companies, First Nations, foundations, amongst others;

- 47 credentials developed in whole or part via OPDF;

- 355 courses, 12 workshops, 19 Web sites/tools, and 396 course components (learning objects, labs, textbooks, manuals, videos) developed across almost all academic fields of study;

- $\quad 100 \%$ licensed for open free sharing and reuse by all post-secondary. (BCcampus OPDF, 2011)

The J ISC OER program focuses not just on generating OER academic resources for use by teachers and students but on exploring a whole range of issues related to OER. A quantitative count of product outputs coming out of the JISC OER program is not readily available, but in addition to actual curricula the outputs include research reports and guidelines around

$$
\begin{aligned}
& \text { - } \quad \text { developing, managing, and sharing OER; } \\
& \text { - } \quad \text { gusiness cases and benefits; } \\
& \text { - } \quad \text { guidance and support; }
\end{aligned}
$$




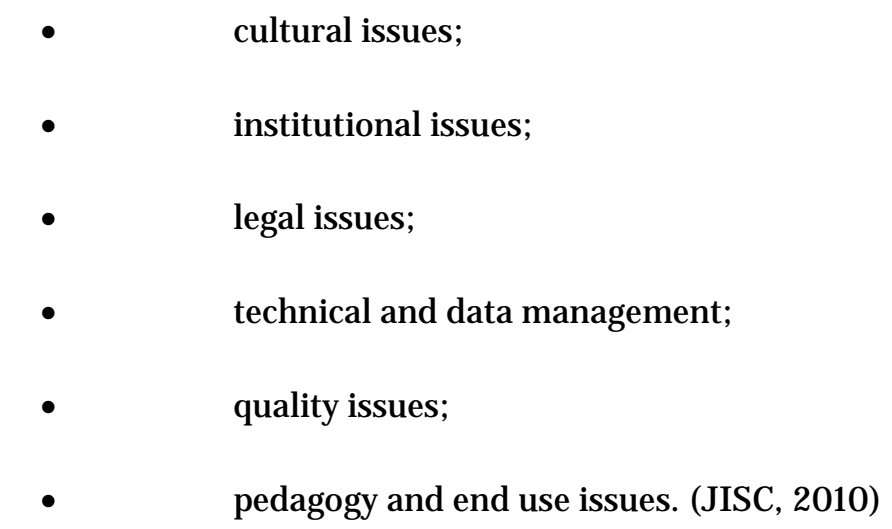

The US Department of Labor TAACCCT initiative is just getting underway so there are no product outputs yet but the focus is on curricula resources not research studies.

The longest OER publicly funded initiative of these three is the one in $\mathrm{BC}$, which has been underway for eight years. To date, public funding for OER development is one time only funding not built in to ongoing operational budgets. How long incentive public funding for OER should continue and what form that funding should take is a matter of government policy and action. Each of the initiatives in this paper has to show results and impact against strategic goals yearly to convince public funders that ongoing investment is worthy.

The US Department of Labor TAACCT program has met with some resistance. The House Appropriations Committee just released the draft fiscal year 2012 Labor, Health and Human Services (LHHS) funding bill. The legislation includes funding for programs within the Department of Labor, the Department of Health and Human Services, the Department of Education, and other related agencies. Included in this bill is the following provision, which would appear to strip the ability of the DOL to support any further OER investments:

SEC. 124. None of the funds made available by this Act for the Department of Labor may be used to develop new courses, modules, learning materials, or projects in carrying out education or career job training grant programs unless the Secretary of Labor certifies, after a comprehensive market-based analysis, that such courses, modules, learning materials, or projects are not otherwise available for purchase or licensing in the marketplace or under development for students who require them to participate in such education or career job training grant programs. (US Congress, 2011)

It will be interesting to see whether this language remains in the bill as it moves through subcommittee to full committee for approval. 
The language in this bill asserts that government funding should not be made in areas where there is an established industry with product already existing for purchase or already under development. While this may bolster the traditional publishing industry's position it does so at the expense of the entire public and sacrifices the goals of providing more and better education for more people. It also impedes the new business model opportunities that OER brings.

OER change education and by extension change the industries that support education. All governments must decide for themselves the best use of public funds. At the core of this decision must be the benefits to all citizens not just industry. The implications affect not just the education of citizens of a particular country but the education of all around the world. NOTE : In the months after this article was written the LHHS funding bill was defeated.

\section{Strategic Goals}

All three of the OER case studies being explored in this paper are making incentive funds available through calls for proposals targeted at post-secondary institutions. In addition to specifying funding priorities and funding award amounts, calls for proposals are used by public funders to describe eligibility, information on the application and submission process, and the criteria against which applications will be reviewed, and to provide additional resources of interest to applicants.

Public funders have strategic goals for the incentive OER funding they provide. Strategic goals establish a focus and purpose for OER and are usually tied to meeting the needs of the nation, state, or province providing the funds.

Here are strategic goal samples from the three OER initiatives this paper is focused on.

\section{BCcampus}

There are three strategic goals associated with the BCcampus OER Online Program Development Fund (OPDF).

\section{Partnerships}

The OPDF is primarily focused on supporting multiple public postsecondary institutional partnerships for development of online learning resources that fulfill a mutual academic need. Partnering involves pooling of expertise and developing online resources that all partner institutions subsequently use. 


\section{Credentials}

A goal of the BCcampus OPDF is to increase credential opportunities available to students throughout the province. The focus is on developing resources that are for credit and contribute to a credential. Credentials are developed through the BCcampus OPDF in four ways.

a) A single round of funding for development of all the courses required for a complete credential.

b) A complete credential is built out gradually through multiple rounds of funding.

c) The OPDF provides funding needed for development of the last few courses required to make the complete credential online.

d) The OPDF creates a number of online courses used across multiple credentials or serving as building blocks for creating credentials.

A summary of credentials the OPDF has contributed to the development of so far can be found at http:// opdf.pbworks.com/OPDF-Outcomes-Analysis.

3. Sharing and Reuse

All resources developed through the OPDF are licensed for free reuse, revision, remix, and redistribution. All resources are openly licensed.

When OPDF resources are fully developed they are put in the BCcampus Shareable Online Learning Resources (SOL*R) repository (http://solr.bccampus.ca) where they become available for review and download.

The OER movement to date is characterized by a lot of development of new OER resources but not a lot of reuse of OER developed by others. The OER field needs to move from not invented here to proudly borrowed from there. To help make this happen the 2010 round of BCcampus OER funding incentivized reuse by requiring applicants to show how new online learning resources developed through 2010 OPDF funding will be integrated with previously funded OPDF resources, or other OER from around the world. The OPDF is seeking to minimize duplication and maximize sharing and reuse. (BCcampus, 2011)

The joint J ISC/ Higher Education Academy Open Educational Resources Pilot Program has been designed to support institutions, consortia, and individuals to release open educational resources for use and repurposing worldwide, by assisting the development 
of appropriate processes and policies to make this process an integral part of the learning material creation workflow.

Strategic goals for the pilot year were to understand the most effective ways of supporting this aim, as a precursor to a longer program to promote the embedding of these processes across institutions.

JISC's objectives in investing in this area are to promote the sharing and reuse of learning resources and to provide a reputational benefit to UK higher education through the promotion of high quality learning resources world wide.

J ISC expects to see benefits to the institutions involved and the UK higher education sector as a whole in terms of overseas recruitment and academic reputation as a result of the work started by this program (J ISC, 2008).

The pilot phase was followed by a second phase (2010-2011) which built on and expanded the work of the pilot phase through research and technical work examining the discovery and use of OER - specifically by academics.

In October 2011 J ISC announced a third phase. The J ISC OER phase three strategic goals are around identified priority areas that will have the greatest impact and reach. These are:

a. develop post-graduate certificates to incorporate open access approaches,

b. embed development of open practices into accredited continuing professional development for academics,

c. embed OER through institutional change models,

d. employ innovative approaches to extend OER beyond traditional HE practice. (J ISC, 2011)

\section{US Department of Labor Trade Adjustment Assistance Community College and Career Training (TAACCCT) Grants Program}

TAACCCT provides eligible institutions of higher education with funds to expand and improve their ability to deliver education and career training programs that can be completed in two years or less, and that result in skills, degrees, and credentials that prepare program participants for employment in high-wage, high-skill occupations, and are suited for workers who are eligible for training under the TAA for Workers program. TAACCCT funds are capacity building grants strategically targeted to assist workers adversely affected by trade agreements. 
There are four strategic priorities for the TAACCCT program: 1) accelerate progress for low skilled and other workers, 2) improve retention and achievement rates to reduce time to completion, 3) build programs that meet industry needs including development of career pathways, and 4) strengthen online and technology enabled learning.

Grant recipients are expected to use data and evidence in identifying areas of development and in assessing what course designs work or don't work. At least one employer must be involved in the program to ensure it is something industry wants. Retention, accelerated time to completion, credential attainment, and job placement are key outcomes sought.

All TAACCCT initiatives are expected to meet accessibility and interoperability standards and to produce OER licensed using Creative Commons (CC-BY) (US Department of Labor, 2011).

\section{Conclusion}

Early OER developments supported by foundations have established a large pool of educational resources and a growing understanding of OER potential and benefits. Grassroots development of OER generated declarations of principle that articulate those benefits. In parallel to foundation-supported initiatives a small number of public governments initiated OER support via policy and incentive funding. Having established a strong OER foundation there is a growing awareness that government can generate significant public benefits by supporting OER through policy, guidelines, and incentive funding. UNESCO, the Commonwealth of Learning, and others are pushing for widespread government endorsement of OER.

As more governments adopt the UNESCO-COL OER guidelines, participation and engagement of the global education community in the OER starts to take place and OER practices become integrated into every day operations, the source and form of public support and funding will diversify. Funding allocated to OER will not just come as grants from government but will come from time investments of individuals, standard educational practices of faculty and students, and strategic goals set not just by government but by schools, colleges, and universities of all kinds. Coalitions and collaborations will form among education providers globally. These international OER partnerships will be the norm and require new models of funding based on collaboration as opposed to current models, which foster competition.

By describing policy, funding, and strategic goals associated with three public OER initiatives this paper helps others in governments, municipalities, and institutions understand their role and the steps they can take to implement and operationalize OER. 


\section{References}

BCcampus (2011). BCcampus 2010 Online Program Development Fund Call For Proposals. Retrieved from http:// opdf.pbworks.com/ w/ page/30172279/2010\%20OPDF

BCcampus OPDF (2011). Online Program Development Fund. Retrieved from http:// www.bccampus.ca/online-program-development-fund opdf-2/

Carlyle, R. (2011). \$64 million for out-of-date and educationally generic textbooks? Here's a new approach. Retrieved from http:// reuvencarlyle36.com/2011/ 10/14/64-million-for-out-of-date-andeducationally-generic-textbooks-heres-a-new-approach/

Casserly C., \& Smith, M. (2008). Revolutionizing education through innovation: Can openness transform teaching and learning? In T. Iiyoshi \& M. S. V. Kumar (Eds.), Opening up education: The collective advancement of education through open technology, open content, and open knowledge (pp. 261- 275). Cambridge, MA: MIT Press.

Daniel J ., \& Uvalić-Trumbić, S. (2011). UNESCO-COL guidelines for open educational resources (OER) in higher education. Retrieved from http://oerworkshop.weebly.com/guidelines-for-oer-in-higher-education.html

J ISC. (2008). Briefing paper on open educational resources. Retrieved from http:// www.jisc.ac.uk/media/documents/funding/2008/12/ oerbriefingv4.doc

J ISC. (2009). Pilot programme - OER release. Retrieved from the Open Educational Resources InfoKit.

https://openeducationalresources.pbworks.com/w/ page/ 24838092/ Pilot\%20P rogramme\%20-\%200ER\%20Release

J ISC. (2010). Open Educational Resources InfoKit Pilot Programme - OER release outputs. Retrieved from https:// openeducationalresources.pbworks.com/ w/ page/26400506/ Pilot\%20P rogramme\%20-\%20OER\%20Release\%20Outputs

J ISC. (2011). HEA/J ISC Open Educational Resources (OER) Phase Three Programme: Embedding and sustaining change. Retrieved from http:// www.jisc.ac.uk/media/documents/funding/2011/ 08/OERProgrammePh ase3FINAL.pdf

New Zealand Government. (2010). New Zealand Government Open Access and Licensing framework (NZGOAL). Retrieved from http://ict.govt.nz/ guidanceand-resources/information-and-data/nzgoal 
Sao Paulo. (2011). Decree on Open Educational Resources. Retrieved from http:// rea.net.br/ 2011/ 10/ 03/ decreto-sobre-rea-em-vigor-em-sao-paulo/

Shuttleworth Foundation, Open Society Institute. (2007). Cape Town Open Education Declaration. Retrieved from http:// www.capetowndeclaration.org/ read-thedeclaration

Stacey, P. (2010). Foundation funded OER vs. tax payer funded OER - A tale of two mandates. Universitat Oberta de Catalunya, Open Ed Conference 2010 Proceedings. Retrieved from http:// hdl.handle.net/10609/5241

US Congress (2011). Bill making appropriations for the Departments of Labor, Health and Human Services, and Education, and related agencies for the fiscal year ending September 30, 2012, and for other purposes. Retrieved from http://appropriations.house.gov/UploadedFiles/FY_2012_Final_LHHSE.pdf page 37.

US Department of Labor (2011). Notice of Availability of Funds and Solicitation for Grant Applications for Trade Adjustment Assistance Community College and Career Training Grants Program. Retrieved from http:// www.doleta.gov/grants/pdf/ SGA-DFA-PY-10-03.pdf

\section{Athabasca University $\mathbf{I}$}

(). (1) 